\title{
Recurrent hydatiform mole: a rare case report
}

\section{Shaifali Kundan Patil*, Jaishree G. Narshetty, Gursimran Baldev Singh, Nidhi Sudhakar Kurkal}

Department of Obstetrics and Gynecology, MGM Hospital, Kalamboli, Navi Mumbai, Maharashtra, India

Received: 5 May 2013

Revised: 28 May 2013

Accepted: 8 June 2013

\section{*Correspondence:}

Dr. Shaifali Kundan Patil,

E-mail: patilshaifali@gmail.com

(C) 2013 Patil SK et al. This is an open-access article distributed under the terms of the Creative Commons Attribution Non-Commercial License, which permits unrestricted non-commercial use, distribution, and reproduction in any medium, provided the original work is properly cited.

\begin{abstract}
Molar pregnancy is characterized histologically by abnormalities of the chorionic villi that consist of trophoblastic proliferation and oedema of villous stroma. The incidence of hydatiform moles in India is 1 in 1000. The incidence of recurrence is 1 in 60 in a subsequent pregnancy and 1 in 65 in the third pregnancy after two molar pregnancies. The occurrence of hydatiform mole is related to a few risk factors such as smoking, increased paternal or maternal age, and previous history of abortions. Here we report a case of a 29 year old woman with history of four partial moles and two first trimester abortions and her management. The patient finally opted for adoption.
\end{abstract}

Keywords: Recurrent, Hydatiform mole, Genetic predisposition

\section{INTRODUCTION}

Molar pregnancy is characterized histologically by abnormalities of the chorionic villi that consist of trophoblastic proliferation and oedema of villous stroma. ${ }^{1}$ The incidence varies geographically with highest incidence in South east Asian countries. ${ }^{2}$ Studies from the United States and England have found that women with a history of one molar pregnancy (partial, complete, or persistent GTN) have an approximately $1 \%$ chance of recurrence in subsequent pregnancy (compared to a $0.1 \%$ incidence in the general population of the United States). ${ }^{3}$ The recurrence rate is much higher after two molar pregnancies (16 to $18 \%){ }^{4}$ Although most cases are described as having short intervals of time and usually of the same histological type, this is not an unbreakable rule.

\section{CASE REPORT}

Our patient was a 29 year old woman, residing at Navi Mumbai belonging to a lower middle socio-economic class, married since 9 years who came to our OPD with complains of two months amenorrhea followed by bleeding per vaginum and pain in abdomen since 4 days. She gave a history of five previous pregnancies all of which did not continue beyond the first trimester. Of the five, three of the pregnancies were molar pregnancies, one was a blighted ovum and the fifth was a missed abortion. The patient had no other significant past history besides a history of two units of blood transfusions 4 years ago and had no addictions. The patient was undergoing treatment for infertility and had conceived after intrauterine insemination with husband's semen. On per speculum examination, the patient had bleeding. Per vaginum bleeding revealed a bulky uterus of 8-10 weeks gestational age and non-tender fornices. The patient was admitted and an urgent ultrasonography was done. The ultrasonogram revealed gravid uterus. Gestational as well as yolk sac was seen but no foetal pole or cardiac activity was visualized. There was excessive choriodecidual reaction occupying most of the gestational sac with a few cystic areas in between. The features were suggestive of a partial hydatiform mole.

The patient's haemogram revealed a haemoglobin value of $7.6 \mathrm{gm} \%$ and beta-HCG values of 500,000 and normal 
thyroid values. Blood was cross matched for transfusion and the patient was taken up for emergency suction and evacuation of products of conception under ultra sound guidance under short general anaesthesia. The products of conception were sent for histopathology.

Post operatively the patient was transfused one unit of packed cells and was monitored with serial beta HCG levels. After the first 48 hours post operatively, the beta HCG levels dropped to 40,188. Histopathology of the products confirmed the diagnosis of partial hydatidiform mole. The patient was advised karyotyping of both partners which was not done because of financial constraints. Patient was advised to conceive with IVF with donor sperms and donor ova. The patient however opted for adoption of the baby of a first degree relative. The patient currently is asymptomatic with $\beta$ HCG levels with normal limits.

\section{DISCUSSION}

Gestational trophoblastic disease refers to a spectrum of pregnancy related placental tumours. Hydatiform mole is defined as abnormal proliferation of trophoblasts with hydropic degeneration of chorionic villi. Two types of hydatiform moles exist; partial and complete moles. The condition is associated with certain risk factors as in extremes of age. Characteristically, women older than 35 years of age have a relative risk of 2.0, and women over 40 years of age have a 5- to 10-fold increase in incidence. ${ }^{2}$ Paternal age is also a factor which may affect the quality of the spermatozoa. ${ }^{5}$ Other risk factors include use of oral contraceptive pills, ${ }^{6}$ diet, gravidity, ${ }^{7}$ smoking and in extremely rare cases with only 21 reported so far a familial predisposition (Familial recurrent Hydatiform Moles) with a biparental origin may also occur. ${ }^{8}$

The incidence of Hydatiform moles also varies with geographic location with an incidence of 1-2 per 1000 live births in USA, 1 in 1000 in India and as high as 1 in 80 in the Philippines. In Europe, 100 cases of Hydatidiform Mole per 100000 pregnancies have been reported, while the corresponding estimates from Asia range from 100 to 1000 per 100,000 pregnancies. In case of subsequent pregnancies, with a history of one previous molar conception, the risk is 1 in 60 and in case of two previous molar pregnancies the incidence increases upto 1 in 6.4 pregnancies. ${ }^{8,9}$ While a complete mole occurs due to the fertilization of an egg, from which the nuclear material has been lost or inactivated by a single sperm having 23,XX chromosomes which duplicates to $46, \mathrm{XX}$, or less frequently, fertilization occurs with two sperms resulting in either $46 \mathrm{xx}$ or $46 x y$ heterozygous chromosomal constitution. ${ }^{10}$ in a partial mole maternal chromosomes are present and the condition arises by diandry (one maternal and two paternal sets of chromosomes). ${ }^{11}$

A hydatiform mole classically presents with a period of amenorrhea lasting from 1-2 months with a history of pain in abdomen and bleeding per vaginum of various degrees and in case of a complete mole, may be classically associated with passage of grape like vesicles from the vagina. There is usually an associated increase in nausea and vomiting (hyperemesis gravidarum) triggered by the highly increased beta HCG levels. The uterus is large for gestational age and is dough like in consistency. Foetal parts cannot be felt and foetal heart sounds are not heard. Hydatiform moles predispose to other systemic disorders such as thyrotoxicosis, preeclampsia and pulmonary embolization. However molar pregnancy does not have any direct adverse effects for subsequent obstetric health. ${ }^{8}$

Once the diagnosis has been confirmed with a ultrasonogram and beta HCG levels, the patient should be taken up for termination of pregnancy by suctionevacuation keeping in mind the real possibility of haemorrhage and hence cross matching adequate amount of blood products. The role of prophylactic chemotherapy has now fallen into disuse. The patients are preferably followed up with serial beta HCG levels at intervals of a week until six weeks after values return to normal and then monthly for six months. Chemotherapy is given only to those women who have poor follow up or when beta HCG levels reach a plateau. Multiagent chemotherapy is used to treat high-risk GTN, defined as stage IV disease or stage II-III disease with a Prognostic Index Score of 7 or above, as well as PSTT and treatment-refractive lowrisk disease. Again, a wide variety of regimens are employed worldwide, with very little evidence to show superiority of any one regimen. The most widely used multiagent chemotherapy regimen EMA-CO-consists of: etoposide, methotrexate, actinomycin D, cyclophosphamide, and vincristine (Oncovin). It achieves a 5-year-survival rate of $86.5 \%$ and is a relatively welltolerated regimen, with alopecia being the commonest side-effect, high-grade haematologic toxicities experienced by less than $2 \%$ of patients, and more than half of patients retaining their fertility. ${ }^{12}$ Women who receive chemotherapy for GTD are likely to have an earlier menopause. ${ }^{13}$ Furthermore, multiagent chemotherapy which includes etoposide increases the risk of developing secondary cancers, such as acute myeloid leukemia, colon cancer, melanoma, and breast cancer for those who survive more than 25 years. ${ }^{14}$ These risks would necessitate long-term follow-up of these patients treated with chemotherapeutic agents. Both forms of moles are potentially malignant. The overall risk of requiring chemotherapy after a complete mole was $13.6 \%$ and $1.1 \%$ for partial mole, while the risk of a further molar pregnancy in the next conception was 1:68 but each of these figures have considerable variations with age. These modern statistics on molar pregnancy risks and outcomes should be of value to clinicians and their patients, while discussing this rare diagnosis. ${ }^{16}$ The risk of gestational trophoblastic neoplasia for partial mole is $<5-10 \%$ and that of complete mole is $20 \%$. The risk of recurrence of hydatidiform mole is $0.5-2.8 \%$ with a subsequent greater risk of developing invasive mole or 
choriocarcinoma. Lorigan et al. analysed the characteristics of women who developed a second molar pregnancy after a previous episode of gestational trophoblastic disease and concluded that $5.7 \%$ of patients required chemotherapy for the second mole. Patient with partial mole also had a recurrent partial mole. ${ }^{18}$

Assessment of any potential increased risk of molar pregnancy associated with ART is difficult. Theoretically, the use of immature ova after ovulation induction or the disruption of meiosis and the loss of maternal chromosomes as a result of oocyte handling or degeneration could increase the risk of a complete mole. There is limited information available about women receiving ovulation induction. However the use of modern molecular biology techniques, preimplantation diagnosis and ICSI may provide further insights into the disease with possible strategies for prevention in women with recurrent molar pregnancies. ${ }^{15}$ Intracytoplasmic sperm injection (ICSI) coupled with preimplantation confirmation of diploidy (guards against partial moles) and selection against transfer of 46XX embryos (prevents complete moles) was employed to prevent a repeat molar pregnancy. ${ }^{19}$

Karyotyping of both partners should ideally be done. Genetic studies suggest mutations in the NLRP7 gene, also known as NALP7 gene, which is located on chromosome 19q13.3-q13.4, a maternal gene, as a cause of Familial biparental Hydatidiform Mole, and possibly responsible for causing recurrent spontaneous abortions, stillbirths, and intrauterine growth retardation. ${ }^{8}$ Two NLRP7 mutations have been detected. In the first, sequencing identified a homozygous 2 bp deletion in the seventh coding exon of NLRP7, while a homozygous Gto-A substitution in the third coding exon of NLRP7 was detected in the second. Both of them result in a truncated protein. The two mutations have not been previously described in the literature. ${ }^{21}$

\section{CONCLUSION}

Recurrent hydatiform moles both partial as well as complete have similar prognosis and incidence rates with most women having the same histological type on recurrence. The management has to be individualized according to the patient's profile and whether or not she desires a future pregnancy. Chemotherapy is a good option for such patients. Inspite of the increase in a few risk factors such as a tendency for increased age of child bearing, the incidence of gestational trophoblastic diseases has decreased over the years. The potential malignant transformation and the genetic predisposition must be kept in mind while dealing with such cases and patients should undergo proper genetic counseling and follow up.

\section{REFERENCES}

1. Cunningham FG, Leveno KT, Bloom SL, Hauth JC. Williams Obstetrics. 23 ${ }^{\text {rd }}$ edition. Vol. 2. New York, NY, USA: McGraw-Hill; 2009:257-64.

2. Palmer JR. Advances in the epidemiology of gestational trophoblastic disease. J Reprod Medicine 1994;39:155-62.

3. R.S. Berkowitz, Z. S. Tuncer, M. R. Bernstein, and D. P. Goldstein, "Management of gestational trophoblastic diseases: subsequent pregnancy experience," Seminars in Oncology, vol. 27, no. 6, pp. 678-685, 2000.

4. A. D. Altman, B. Bentley, S. Murray, and J. R. Bentley, "Maternal age-related rates of gestational trophoblastic disease," Obstetrics and Gynecology, vol. 112, no. 2, pp. 244-250, 2008.

5. Levitas E, Lunenfeld E, Weisz N, Friger M, Potashnik G. Relationship between age and semen parameters in men with normal sperm concentration: Analysis of 6022 semen samples. Andrologia 2007;39:45-50.

6. Palmer JR, Driscoll SG, Rosenberg L, Berkowitz RS, Lurain JR, Soper J, et al. Oral contraceptive use and risk of gestational trophoblastic tumours. J Natl Cancer Inst 1999;91:635-40

7. Pour Reza M, Agheli N, Baghefi SB. Serum creatinine and urea and protein level changes in hydatidiform mole. JAMA 1974;230:580-1.

8. Moglabey YB, Kircheisen R, Seoud M, El Mogharbel N, Van den Veyver I, Slim R. Genetic mapping of a maternal locus responsible for familial hydatidiform moles. Hum Mol Genet 1999;8:667-71.

9. Altieri A, Franceschi S, Ferlay J, Smith J, La Vecchia C. Epidemiology and aetiology of gestational trophoblastic diseases. Lancet Oncol 2003;4:670-8.

10. Sebire NJ, Fisher RA, Foskett M, Rees H, Seckl MJ, Newlands ES. Risk of recurrent hydatiform mole and subsequent pregnancy outcome following complete or partial hydatiform molar pregnancy. BJOG 2003; 110:22-6.

11. S. D. Lawler, R. A. Fisher, and J. Dent, "A prospective genetic study of complete and partial hydatidiform moles," American Journal of Obstetrics and Gynecology, vol. 164, no. 5, pp. 1270-1277, 1991.

12. E. Garner, "Malignant gestational trophoblastic disease: staging and treatment," in UpToDate [Textbook of Medicine], B. Goff, S. Falk, and D. M. F. Savarese, Eds., UpToDate, Waltham, Mass, USA, 2011.

13. S. D. Lawler, R. A. Fisher, and V. J. Pickthall, "Genetic studies on hydatidiform moles. I. The origin of partial moles," Cancer Genetics and Cytogenetics, vol. 5, no. 4, pp. 309-320, 1982.

14. P. K. Sand, J. R. Lurain, and J. I. Brewer, "Repeat gestational trophoblastic disease, "Obstetrics and Gynecology 1984;63:140-4. 
15. Reubinof BE, Lewin A, Verner M, Safran A, et al. Intracytoplasmic sperm injection combined with preimplantation genetic diagnosis for prevention of recurrent gestational trophoblastic disease. Hum Reprod 1997;12(4):805-09.

16. Seckl MJ, Rustin GJ. Late toxicity after therapy for gestational trophoblastic tumours. In: Hancock BW, Newlands ES, Berkowitz RS, Cole LA, editors. Gestational Trophoblastic Disease. 3rd ed. London: International Society for the Study of Trophoblastic Disease; 2003 p. 470-84.

17. Rustin GJS, Newlands ES, Lutz JM, Holden L, Bagshawe KD, Hiscox JG, et al. Combination but not single agent chemotherapy for gestational trophoblastic tumours (GTT) increases the incidence of seconds tumours. J Clin Oncol 1996;14:2769-73.

18. Lorigan PC, Sharma S, Bright N, Coleman RE, Hancock BW. Characteristics of women with recurrent molar pregnancies. Gynecol Oncol 2000; 78:288-92.

19. Pregnancy After Assisted Reproductive Technology Edited by Eric R. M. Jauniaux, Botros R. M. B. Rizk, Cambridge University Press 2012.

20. Savage PM, Sita-Lumsden A, Dickson S, Iyer R, Everard J, Coleman R, et al. The relationship of maternal age to molar pregnancy incidence, risks for chemotherapy and subsequent pregnancy outcome. J Obstet Gynaecol. 2013 May;33(4):406-11.

21. Abdalla EM, Hayward BE, Shamseddin A, Nawar MM. Recurrent hydatidiform mole: detection of two novel mutations in the NLRP7 gene in two Egyptian families. Eur J Obstet Gynecol Reprod Biol 2012;164:211-5.

DOI: $10.5455 / 2320-1770$. ijrcog20130937

Cite this article as: Patil SK, Narshetty JG, Singh GB, Kurkal NS. Recurrent hydatiform mole: a rare case report. Int J Reprod Contracept Obstet Gynecol 2013;2:433-6. 